\title{
Census 2011 and Child Sex Ratios in Tamil Nadu: A Comment
}

\author{
Sharada Srinivasan* and Arjun S. Bedi ${ }^{\ddagger}$
}

\begin{abstract}
Inspired by Narayana (2008), published in this journal, this comment revisits the conclusion of a policy-driven decline in daughter elimination in the south Indian state of Tamil Nadu using recently released data from Census 2011. Consistent with Narayana's work we find evidence to support the conclusion that government and NGO interventions have played a role in reducing gender differences in survival.

Word count: 2663 (without tables and figures)

Forthcoming in Journal of Human Development and Capabilities. Accepted for publication on August 6, 2012.
\end{abstract}

\footnotetext{
* York University, Canada, em: sharada@yorku.ca ‡International Institute of Social Studies, Erasmus University Rotterdam, The Netherlands, em: bedi@iss.nl. We thank two anonymous referees for useful comments.
} 
A well-known demographic feature in many Asian countries is the lower proportion of females to males. ${ }^{1}$ A substantial proportion of this anomaly may be attributed to the differential survival rates of girls and boys due to daughter elimination in the form of sex selection, infanticide and neglect (see Sen, 1990; Jha et al., 2006). Despite the inherent equity concerns and the grim possibilities emanating from male surplus and female deficit, efforts to prevent daughter elimination in India and elsewhere are wanting. In India, while governments at the centre and in different states have put in place some responses, little is known about the effect of these policies on daughter deficit. ${ }^{2}$

Exceptions are the work by Narayana (2008) and Srinivasan and Bedi (2011). In the context of an examination of country-wide patterns in gender differences in infant mortality, Narayana (2008) analyses the case of Tamil Nadu and suggests that policy interventions such as the Cradle Baby Scheme, legal measures and social awareness campaigns targeted at specific districts have played an important role in reducing gender differences in infant mortality, and that Tamil Nadu's experience may have important lessons for policy responses to daughter deficit. Srinivasan and Bedi (2011) extend Narayana's exploratory analysis in several ways. Narayana (2008) relied only on the 1998 round of the Vital Events Survey (VES) and focused on gender differences in infant mortality. In contrast, Srinivasan and Bedi analyse five editions of the VES data covering the birth years 1996 to 2003 to examine gender differences in both infant mortality and sex ratios at birth. Supporting Narayana's (2008) conclusions about the role

\footnotetext{
${ }^{1}$ For an account of trends in the extent of missing women and changes in sex ratio at birth in different countries see Klasen and Wink (2003) and Guilmoto (2009).

${ }^{2}$ The most common response appears to be cash transfer programs for daughters. There are at least 15 such cash transfer schemes operating in different parts of the country, Sekher (2010).
} 
of policy, their analysis shows a sharp decline in daughter deficit in districts which were the focus of government and NGO efforts to tackle daughter elimination. Inspired by the papers referred to above, this comment re-visits the conclusion of a policy-driven decline in daughter elimination. The main merit of this comment is that it relies primarily on more recent, comprehensive and potentially more reliable census data (collected in 2001 and 2011) as opposed to somewhat dated (1996 to 2003) survey data.

Provisional estimates based on Census 2011 show that the Indian population sex ratio increased from 933 in 2001 to 940 in 2011 after reaching a low of 927 in 1991. In contrast, the sex ratio in the age group 0 to 6 (child sex ratio) continued to decline, albeit at a decreasing rate as compared to the previous decade, that is, from 927 in 2001 to 914 in 2011 (see Table 1). In terms of the distribution of the decline, 27 of the 35 states/union territories exhibit a decline in the ratio (Office of the Registrar General, 2012), and despite the increase in some (eight) states, there is also a clear increase in the geographical spread of daughter deficit as compared to the 2001 census. In short the blurring of the so-called diagonal divide - more masculine sex ratios in the north-west as compared to the south-east (Dyson and Moore, 1983) — continues.

Unlike the sex ratio at birth which is expected to be 952 , there is no corresponding figure for the 0-6 sex ratio (child sex ratio). However, based on an expected sex ratio at birth (SRB) of 952 and the typically higher rates of male infant and child mortality, the lower limit for the 0-6 sex ratio in populations without any pre- or post-birth interference should be 952. According to Census 
2011, only nine of the 35 states/union territories have sex ratios that are higher than this threshold. ${ }^{3}$

A state that does not follow the pattern of decline is Tamil Nadu. While the 0-6 ratio in Tamil Nadu has never fallen to the levels observed in north-west India, between 1961 and 2001 the state had witnessed a decline in the 0-6 sex ratio from 985 to 942 . Hence the increase in the 0-6 sex ratio from 942 in 2001 to 946 in 2011 marks a break from this declining trend. While the change may seem small, a district level analysis of the source of the increase coupled with the knowledge of the various post-2001 interventions that have been implemented in the state to reduce daughter elimination reveals a picture worth examining.

To begin with we provide an account of the various interventions implemented in the state mainly between 2001 and 2011. We deal with this rather briefly as these interventions have been discussed at length in Srinivasan and Bedi (2011). In part, sparked by the decline in the 0-6 sex ratio in Tamil Nadu between 1991 and 2001, in early 2001 the state government re-launched several schemes and initiatives designed to prevent daughter elimination. These schemes included the Cradle Baby Scheme (CBS), the Girl Child Protection Scheme (GCPS) and legal action against female infanticide. In addition to these government interventions, several NGOs were active in the districts of Madurai (including Theni), Salem (including Namakkal) and Dharmapuri. While details differ, broadly NGO approaches consist of three aspects-(i) formation of women's self-help groups (SHGs) for savings and income generation, and to explicitly tackle female infanticide; (ii) identification, monitoring, and

\footnotetext{
${ }^{3}$ States/union territories with 0-6 ratios higher than 952 are Arunachal Pradesh, Mizoram, Tripura, Meghalya, Assam, Chattisgarh, Kerala, Puducherry, and Andaman and Nicobar Islands.
} 
counselling of high-risk (those with more than one daughter) pregnant women and their families on the value of girl children. This is often done with the help of and through SHGs. When counselling, persuasion and emotional appeal fail, the threat of police action is invoked, and (iii) provision of economic support for daughters and their families either through their own programs or through government schemes.

Based on the intensity and range of interventions, and drawing on the information available in and the approach used by Srinivasan and Bedi (2011), we classify the districts into those that were heavily treated (HT) in the sense that these districts were targeted by three government interventions (CBS, GCPS, and legal action) and NGO interventions; lightly treated (LT) districts are those which have access to CBS, GCPS and witnessed legal action but were not targeted by NGO interventions; and minimally treated (MT) districts have access to the CBS, and GCPS but did not witness any legal action and were not targeted by NGO interventions (see Table 2). ${ }^{4}$ A notable aspect emerging from the classification is that (see Table 3, column 2 and Table 4, column 2) both government and NGO interventions were purposively targeted and focused on five districts with the lowest sex ratio at birth and the highest FIMR.

Turning to the source of the state-level improvement in the $0-6$ sex ratio between 2001 and 2011, there are two dimensions. First, the change in the 0-6 sex ratio may be due to a change in the sex ratio at birth, differences in male and female infant (age 0-1) mortality and/or differences in male and female mortality between ages 1 and 5 . Second, and the focus of this comment, is the

\footnotetext{
4 Details on the information used to determine treatment status such as areas of NGO intervention and information on districts which witnessed legal action against infanticide is available in Srinivasan and Bedi (2011).
} 
geographic origin of the changes-that is, which districts account for the observed change. Since census data on sex ratio at birth have not yet been released, we focus on using the available data to identify the geographic source of the change in the $0-6$ sex ratio.

The increase in the state-level 0-6 sex ratio may have occurred due to an increase in the ratio in some districts and/or due to population movements across districts. Consider the figures in Table 3. Column 3 shows district-specific changes in the 0-6 sex ratio between 2001 and 2011 while columns 4 and 5 provide information on the share of the 0-6 population in each district in 2011 and 2001, respectively. As the figures show, the district-level distribution of the total 0-6 population does not change substantially between 2001 and 2011 . Hence, the overall state-level change is almost entirely due to increases in the sex ratio in some districts. ${ }^{5}$ The contribution of each district to the overall four point state-level increase is presented in column 6 and is obtained by multiplying the figures in column 3 and 4 . As a sensitivity check we also carry out the calculation using the share of the 0-6 population in each district in 2001 (see column 7 ).

The sharpest increase in the 0-6 sex ratio takes place in Dharmapuri which experiences an 85 point increase, followed by Salem, Theni and Namakal with increases of 66,46 and 24 points respectively. These four districts are followed by Erode and Krishnagiri (part of Dharmapuri till February 2004). It is probably no coincidence that the sharpest increases are recorded in precisely those districts which fall in the $H T$ category. Madurai which was also heavily treated experiences an increase although not as large as compared to the other

\footnotetext{
${ }^{5}$ The total change in the 0-6 sex ratio which may be attributed to changes in sex ratio as opposed to population movements across districts is 3.65 using the 2011 population distribution and 4.17 using the 2001 population distribution.
} 
four $H T$ districts. In terms of their contribution to the overall increase in the 0-6 sex ratio, the five $H T$ districts account for a 7 point increase in the sex ratio while the lightly or minimally treated districts account for a 3 point decline. The strong link between treatment intensity and the increase in the 0-6 sex ratio is illustrated in Figure 1. The figure clearly shows that the increase in the 0-6 sex ratio emanates from the $H T$ districts, and that changes in the 0-6 sex ratio are not particularly different across the $M T$ and $L T$ districts.

The large increase in the 0-6 sex ratio in the five $H T$ districts is consistent with Narayana's (2008) and Srinivasan and Bedi's (2011) claim of the role of policy in reducing gender differences in infant mortality. Based on various rounds of Vital Events Survey data collected by the state government, districtspecific analysis of SRB and gender differences in infant mortality showed that over the period 1996 and 2003 the SRB did not change much, while gender differences in infant mortality narrowed substantially due to a sharp decline in female infant mortality. For example, in rural Salem, female infant mortality fell from 121 over the period 1996-99 to 45 in 2003. In Dharmapuri the corresponding numbers were 111 to 49 and in Theni 81 to 42 (see Table 4). Figure 2 illustrates these patterns and once again shows that the decline in female infant mortality may be attributed mainly to the heavily treated districts and that the decline in female IMR is not different across $M T$ and $L T$ districts.

The consistency in the pattern of change based on the analyses of the census and VES data is remarkable. Taken together it seems that between 2001 and 2011 the increase in the 0-6 sex ratio may be attributed mainly to a decline in gender differences in infant mortality and in geographical terms entirely to the five $H T$ districts. While the numbers in Table 3 and the figures suggest a strong 
link between changes in child sex ratio and (heavy) treatment status, it is possible that the increases in child sex ratio are not due to the interventions but due to other factors, for instance reversion to the mean, and that this increase may have taken place regardless of the interventions. In the context of the implicit (double-difference) estimator being used in Table 3 this amounts to a violation of the parallel trends assumption. To test for this possibility and to sharpen the analysis, we put together a data set which contains information on child sex ratios from the 1991, 2001 and 2011 censuses and estimate a set of parsimonious ordinary least squares regressions. While this comes at a cost it also has the advantage of allowing us to examine the link between child sex ratios in heavily treated districts and other districts between 1991 and 2001, that is, during a time period when there were no widespread interventions. ${ }^{6}$

Before turning to the regressions consider Table 5 and Figure 3. Table 5 shows that between 1991 and 2001 there is no statistically significant change in the gap in the 0-6 sex ratio between $H T$ and control districts and that the gap only declines between 2001 and 2011. The same point is made in Figure 3 which illustrates that even though in 1991 there was a pronounced gap in the 0-6 sex ratio between $H T$ and control districts there is no tendency for the gap to decline between 1991 and 2001. In other words the figure illustrates that in the absence of interventions the gap in the 0-6 sex ratio between $H T$ and other districts is unlikely to have changed. While the numbers and figures do not constitute a formal test, they do support the idea that the observed change in the child sex ratio between 2001 and 2011 in the $H T$ districts may not be unduly driven by

\footnotetext{
${ }^{6}$ In 1991 the state had only 21 districts as opposed to 32 districts in 2001 and 2011 . To create a compatible data set we aggregated information from the 32 districts to create a 3 period panel data set consisting of 63 observations. The available information does not allow us to map the 21 old districts into the 32 new districts.
} 
mean reversion. Finally, Table 6 provides estimates of the link between $0-6$ sex ratio and a district's intervention status based on three different regression specifications. Regardless of the specification the estimates yield a familiar story. The increase in the overall 0-6 sex ratio between 2001 and 2011 may be attributed mainly to the heavily treated districts. Depending on the specification, on average, the heavily treated districts witness a 34 to 44 point increase in $0-6$ sex ratio. While the lightly treated districts also record an increase in the 0-6 sex ratio this increase is not statistically significant. Overall, the analysis suggests that it is the combination of government and NGO interventions which is responsible for the increase in 0-6 sex ratios.

Notwithstanding these estimates, it is difficult to draw a straightforward cause and effect relationship between interventions and outcomes. At the same time it is also difficult to dismiss the role of interventions in reducing daughter elimination. Indeed, the geographical origins of the state-level increase in the 0-6 sex ratio does suggest that the interventions have played an important role in changing the pattern of continuous decline in the 0-6 sex ratio observed in Tamil Nadu between 1961 and 2001.

\section{References}

Chunkath, Sheela Rani and V.B. Athreya (1997) Female infanticide in Tamil Nadu-some evidence, Economic and Political Weekly, 32(17): WS-21-8.

Dyson, Tim and Mick Moore (1983) On kinship structure, female autonomy and demographic behaviour in India, Population and Development Review, 9(1): $35-60$.

Guilmoto, Christophe Z. (2009) The sex ratio transition in Asia, Population and Development Review, 35(3), pp. 519-549.

Jha, Prabhat, Rajesh Kumar, Priya Vasa, Neeraj Dhingra, Deva Thiruchelvam,Rahim Moineddin (2006) Low male-to-female sex ratio of 
children born in India: National survey of 1.1 million households, the Lancet, 367(9506): 211-218.

Klasen, Stephan and Claudia Wink (2003) "Missing women": revisiting the debate, Feminist Economics, 9(2-3): 263-99.

Narayana, D. (2008) Intensifying infant mortality inequality in India and a reversal by policy intervention, Journal of Human Development, 9(2): 265-281.

Office of the Registrar General, Government of India (2012) Census 2011. http://censusindia.gov.in/2011-prov-results/census2011 PPT paper1.html accessed on April 04, 2011

Planning Commission, (2002) National human development report 2001, Government of India http://planningcommission.nic.in/reports/genrep/nhdrep/nhdreportf.htm.

Premi, M.K. (2001) The missing girl child, Economic and Political Weekly, 36(21): 1875-80.

Sekher, T.V. (2010) Special financial incentive schemes for the girl child in India: A review of select schemes, prepared for the Planning Commission, Government of India in collaboration with United Nations Population Fund.

Sen, Amartya (1990) More than 100 million women are missing, The New York Review of Books, December 20.

Srinivasan, Sharada and Arjun S. Bedi (2009) Tamil Nadu and the diagonal divide in sex ratios, Economic and Political Weekly, 44(3): 56-63.

Srinivasan, Sharada and Arjun S. Bedi (2011) Ensuring daughter survival in Tamil Nadu, Oxford Development Studies, 39(3): 253-283.

Visaria, P. M. (1967) The sex ratio of the population of India and Pakistan and regional variations during 1901-61, in A. Bose (ed.) Patterns of Population Change in India, 1951-61. Bombay: Allied Publishers. 
Table 1

Population Sex Ratio, 0-6 Sex Ratio in India and Tamil Nadu

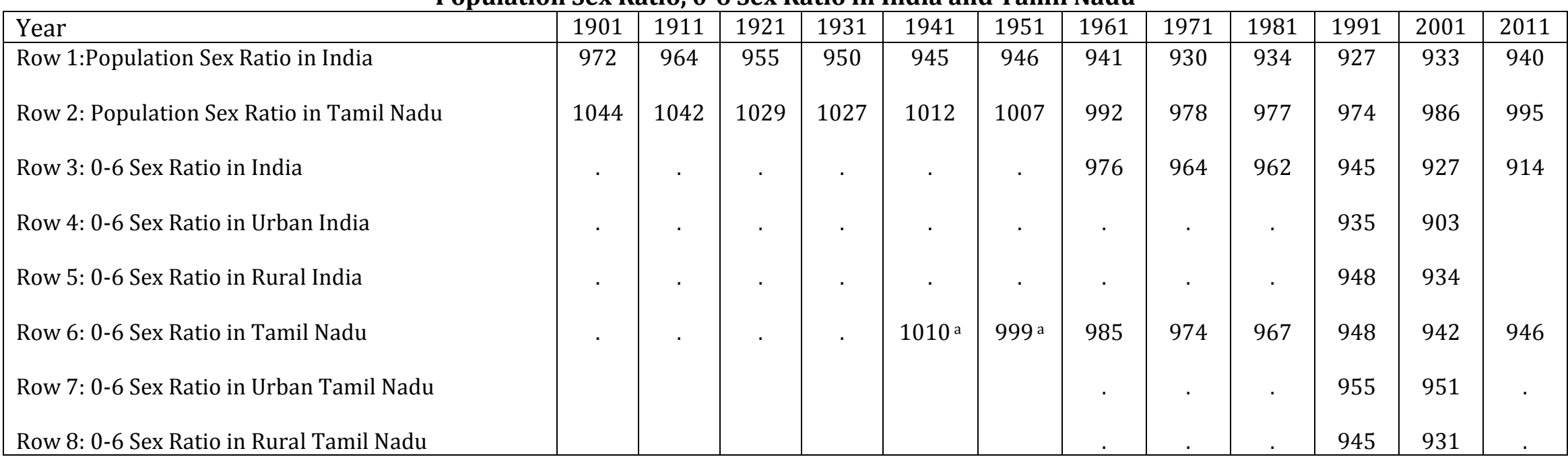

Notes: The ratios are defined as the number of females per 1000 males. a 0-4 sex ratio, from Chunkath and Athreya (1997). Sources: All figures are based on census data. (a) Figures in row 1 and row 2, from 1901 to 1961 are from Visaria (1969). (b) Figures in row 1 and row 2 from 1981 to 2001 are from National Human Development Report 2001, Planning Commission, Government of India (2002). Figures in rows 1 and 2 for 2011 are from http://censusindia.gov.in/2011-prov-results/census2011_PPT_paper1.html (c) Figures in row 3 and row 6 from 1961 to 2001, are from Premi (2001). For 2011 the figures are from the same source as mentioned in (b). (d) Figures in row 4, 5, 7 and 8 are from eCensus India - Issue 15 (2003), Office of the Registrar General, India. 
Table 2

Intervention intensity

\begin{tabular}{|l|c|c|c|l|}
\hline \multicolumn{1}{|c|}{ District } & $\begin{array}{c}\text { Cradle Baby } \\
\text { Scheme/Girl } \\
\text { Child } \\
\text { Protection } \\
\text { Scheme }\end{array}$ & $\begin{array}{c}\text { Evidence of } \\
\text { Legal Action }\end{array}$ & NGOs Active & $\begin{array}{c}\text { Treatment } \\
\text { status }\end{array}$ \\
\hline Dharmapuri & $\mathrm{X}$ & $\mathrm{X}$ & $\mathrm{X}$ & Heavily treated \\
Dindigul & $\mathrm{X}$ & $\mathrm{X}$ & 0 & Lightly treated \\
Madurai & $\mathrm{X}$ & $\mathrm{X}$ & $\mathrm{X}$ & Heavily treated \\
Namakkal & $\mathrm{X}$ & $\mathrm{X}$ & $\mathrm{X}$ & Heavily treated \\
Nilgiris & $\mathrm{X}$ & $\mathrm{X}$ & 0 & Lightly treated \\
Perambalur & $\mathrm{X}$ & $\mathrm{X}$ & 0 & Lightly treated \\
Salem & $\mathrm{X}$ & $\mathrm{X}$ & $\mathrm{X}$ & Heavily treated \\
Theni & $\mathrm{X}$ & $\mathrm{X}$ & 0 & Heavily treated \\
Thiruvannamalai & $\mathrm{X}$ & $\mathrm{X}$ & 0 & Lightly treated \\
Virudhunagar & $\mathrm{X}$ & $\mathrm{X}$ & \\
\hline
\end{tabular}

Notes: $\mathrm{X}$ indicates the presence of an intervention while 0 indicates absence. The remaining districts (not included in this table) are referred to as minimally treated districts and have access to the GCPS and CBS but there is no evidence of legal action and there is no NGO intervention. 
Table 3

District-specific Changes in 0-6 Sex Ratio in 2001 and 2011, Tamil Nadu

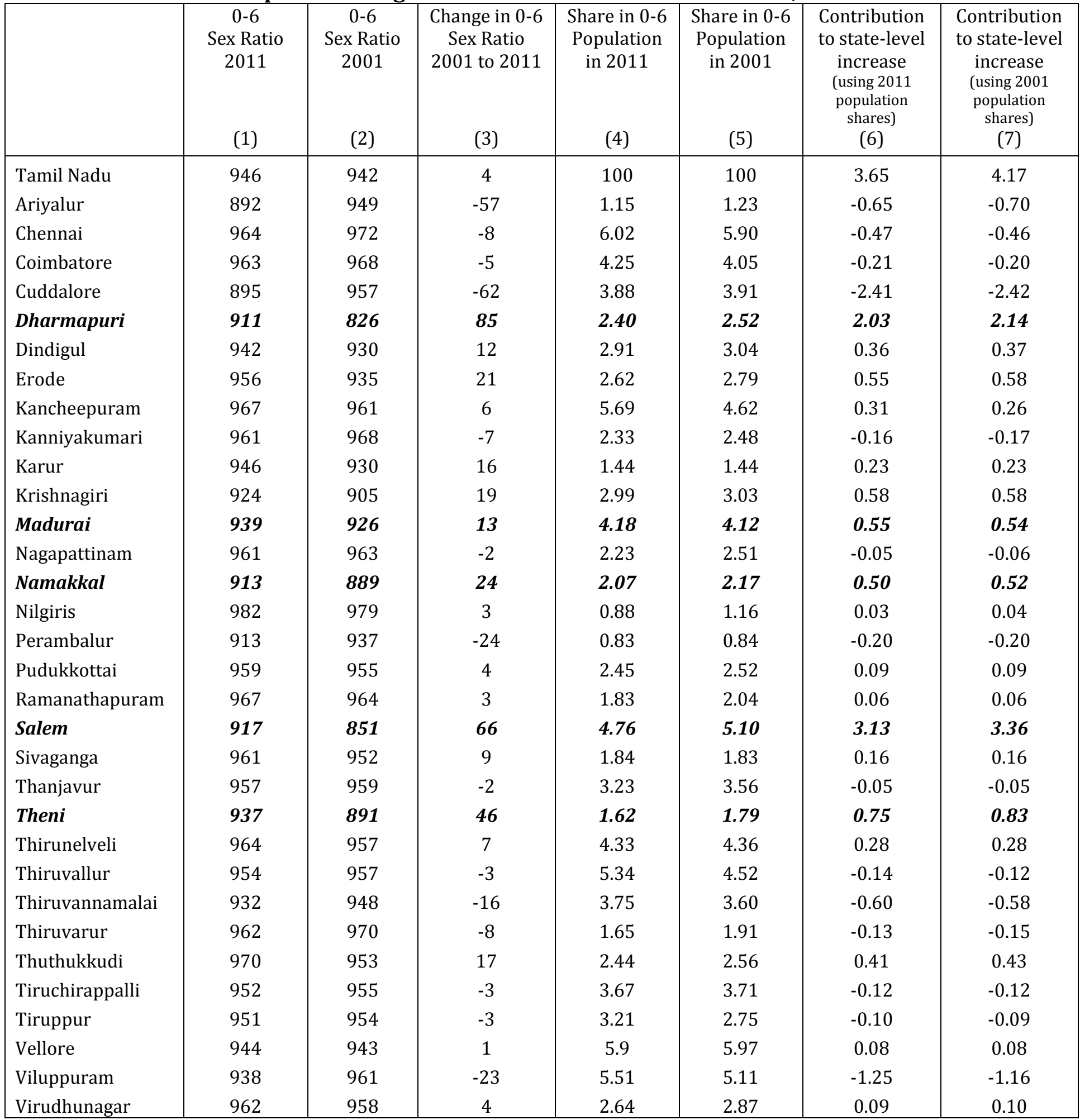

Note: Figures are based on census data. Highlighted text indicates heavily treated districts. 
Table 4

District (Rural) Specific Male and Female Infant Mortality Rates

Tamil Nadu, 1996-1999 and 2003

\begin{tabular}{|c|c|c|c|c|}
\hline & $\begin{array}{c}\text { MIMR } \\
\text { Rural } \\
1996-99 \\
(1)\end{array}$ & $\begin{array}{c}\text { FIMR } \\
\text { Rural } \\
1996-99 \\
(2)\end{array}$ & $\begin{array}{c}\text { MIMR } \\
\text { Rural } \\
2003 \\
(3)\end{array}$ & $\begin{array}{c}\text { FIMR } \\
\text { Rural } \\
2003 \\
(4)\end{array}$ \\
\hline Tamil Nadu & 41 & $48^{*}$ & 33 & $33^{*}$ \\
\hline Coimbatore & 39 & 30 & 25 & 21 \\
\hline Cuddalore & 37 & $36^{*}$ & 32 & 35 \\
\hline Dharmapuri & 56 & 111* & 45 & $49 *$ \\
\hline Dindigul & 43 & $56^{*}$ & 30 & $54^{*}$ \\
\hline Erode & 41 & $41^{*}$ & 34 & 28 \\
\hline Kancheepuram & 30 & 25 & 23 & 22 \\
\hline Kanyakumari & 20 & 19 & & . \\
\hline Karur & 43 & $41^{*}$ & 37 & 35 \\
\hline Madurai & 41 & $58^{*}$ & 30 & $42 *$ \\
\hline Nagapattinam & 37 & 34 & 34 & 30 \\
\hline Namakkal & 43 & 60* & 31 & 26 \\
\hline Nilgiris & 41 & 35 & 32 & 24 \\
\hline Perambalur & 47 & $51 *$ & 31 & $38^{*}$ \\
\hline Pudukottai & 36 & $38^{*}$ & 31 & $35^{*}$ \\
\hline Ramanathapuram & 51 & $47^{*}$ & 37 & 31 \\
\hline Salem & 49 & $121 *$ & 35 & $45^{*}$ \\
\hline Sivaganga & 34 & $36^{*}$ & 28 & 24 \\
\hline Thanjavur & 43 & 34 & 38 & 26 \\
\hline Theni & 48 & $81 *$ & 35 & $42 *$ \\
\hline Thirunelveli & 39 & 35 & 36 & 32 \\
\hline Thiruvallur & 31 & $30^{*}$ & 28 & 24 \\
\hline Thiruvannamalai & 38 & $42^{*}$ & 32 & 34 \\
\hline Thiruvarur & 39 & 32 & 34 & 19 \\
\hline Thuthukudi & 45 & 40 & 33 & 30 \\
\hline Tiruchirapalli & 52 & $48^{*}$ & 29 & $42^{*}$ \\
\hline Vellore & 42 & $56^{*}$ & 36 & $48^{*}$ \\
\hline Villupuram & 48 & $45^{*}$ & 32 & $36^{*}$ \\
\hline Virudhunagar & 39 & $40^{*}$ & 38 & 31 \\
\hline
\end{tabular}

Notes: Infant mortality rate (IMR) is defined as number of infant deaths (age 0-365 days) per 1000 live births. The IMR figures are our calculations based on the Vital Events Surveys, 1996-1999 and 2003. * indicates that the estimated female IMR is greater than the expected female IMR at at least the $5 \%$ level of significance. The expected female IMR is about 80 percent of male IMR (for details, see Srinivasan and Bedi, 2011). Highlighted text indicates heavily treated districts. 
Table 5

0-6 Sex Ratio in Tamil Nadu

(Std. Error)

\begin{tabular}{|l|c|c|c|}
\hline & $\mathbf{1 9 9 1}$ & $\mathbf{2 0 0 1}$ & $\mathbf{2 0 1 1}$ \\
\hline Heavily treated districts & 889 & 881 & 924 \\
& $(8.83)$ & $(7.35)$ & $(7.89)$ \\
\hline Control districts & 962 & 956 & 952 \\
& $(4.09)$ & $(3.46)$ & $(3.67)$ \\
\hline Treated-Control & -72 & -75 & -28 \\
95\% C.I. & $(-93-52)$ & $(-92-57)$ & $(-46-9)$ \\
\hline
\end{tabular}

Note: Figures are based on census data.

Table 6

0-6 Sex Ratio and Intervention Intensity, OLS estimates (std. err.)

\begin{tabular}{|c|c|c|c|}
\hline VARIABLES & (1) & $(2)$ & (3) \\
\hline 2011 & $\begin{array}{c}-8.46^{* * *} \\
(4.27)\end{array}$ & $\begin{array}{l}-1.47 \\
(4.26)\end{array}$ & $\begin{array}{c}3.62 \\
(4.56)\end{array}$ \\
\hline 2001 & $\begin{array}{c}-6.31 \\
(4.27)\end{array}$ & . & . \\
\hline HT.2011 & $\begin{array}{l}42.12^{*} \\
(9.88)\end{array}$ & $\begin{array}{l}44.74^{*} \\
(4.94)\end{array}$ & $\begin{array}{c}34.5^{*} \\
(10.5)\end{array}$ \\
\hline LT.2011 & $\begin{array}{c}15.06^{* * *} \\
(8.12)\end{array}$ & $\begin{array}{c}6.07 \\
(7.74)\end{array}$ & $\begin{array}{c}5.90 \\
(6.76)\end{array}$ \\
\hline HT.2001 & $\begin{array}{l}-2.36 \\
(9.88)\end{array}$ & 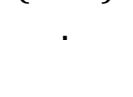 & - \\
\hline LT.2001 & $\begin{array}{c}8.11 \\
(8.12)\end{array}$ & . & . \\
\hline Lagged $0-6$ sex ratio & . & $\begin{array}{c}-0.89 * * \\
(0.27)\end{array}$ & $\begin{array}{l}-0.13 \\
(0.86)\end{array}$ \\
\hline Constant & $\begin{array}{l}945.2^{*} \\
(7.45)\end{array}$ & $\begin{array}{l}833.6^{*} \\
(258.5)\end{array}$ & $\begin{array}{l}120.1 \\
(82.6)\end{array}$ \\
\hline District fixed effects & Yes & Yes & No \\
\hline Observations & 63 & 42 & 42 \\
\hline Adj. R-squared & 0.83 & 0.67 & 0.46 \\
\hline
\end{tabular}


Figure 1

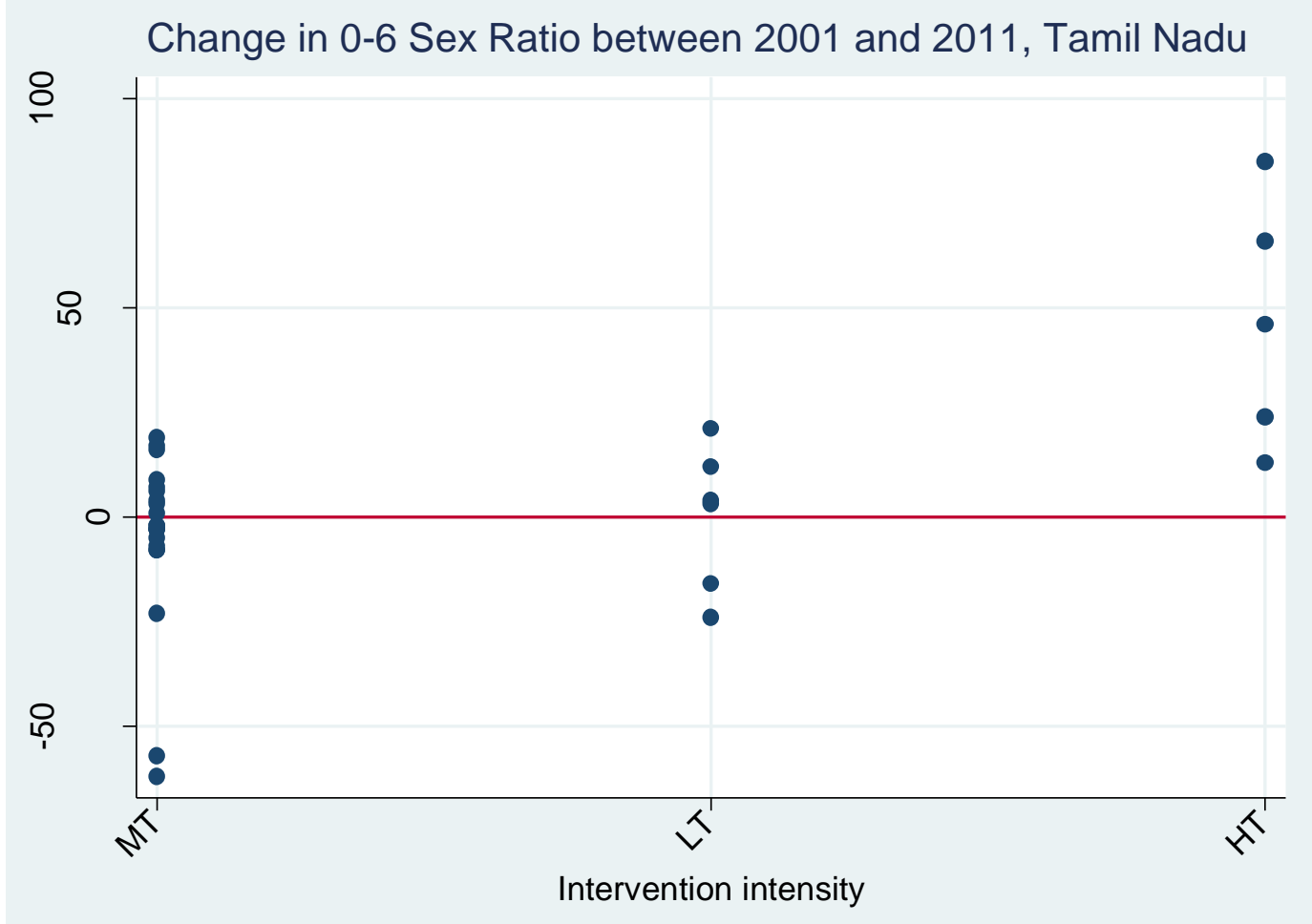

Figure 2

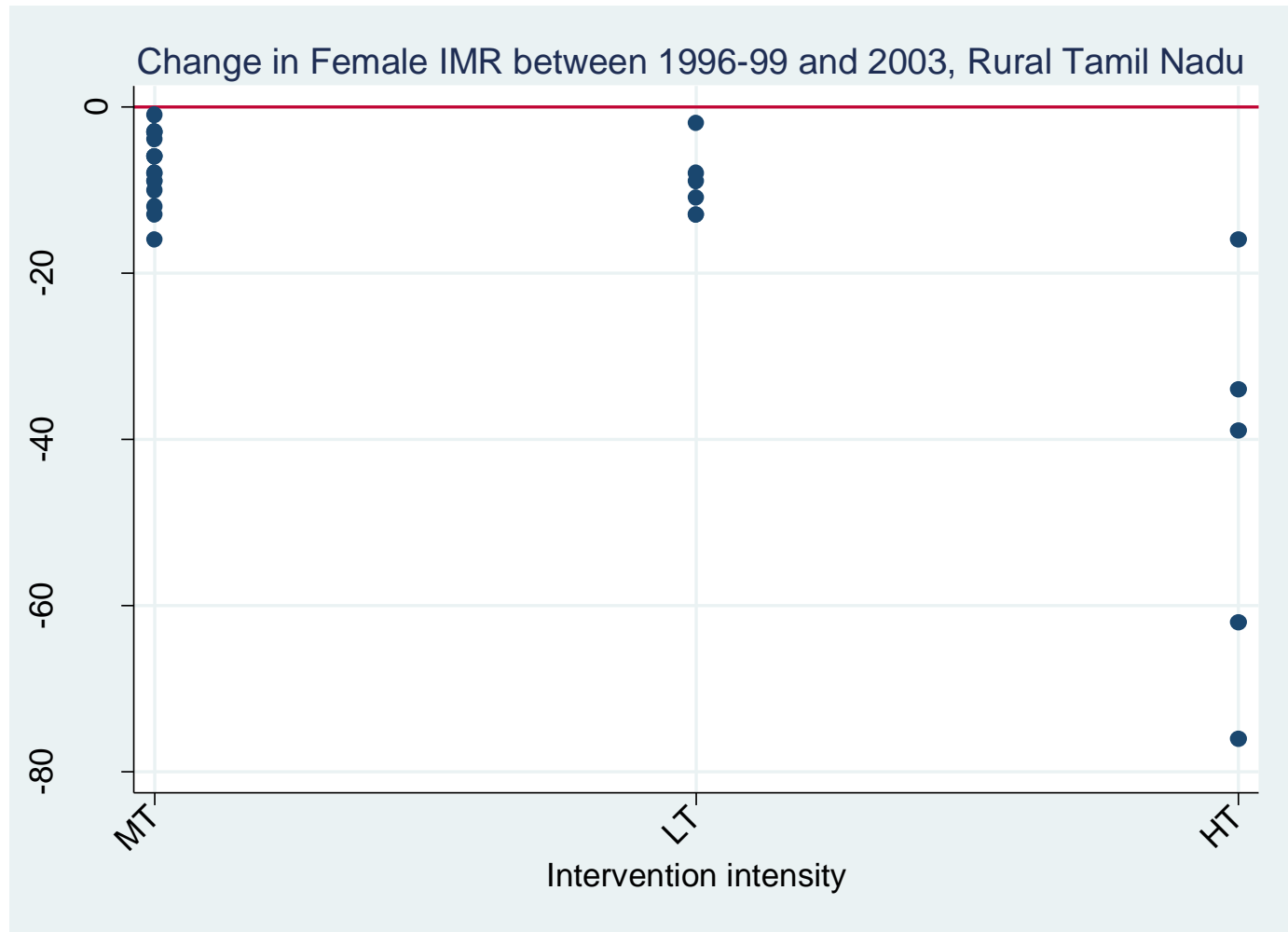


Figure 3

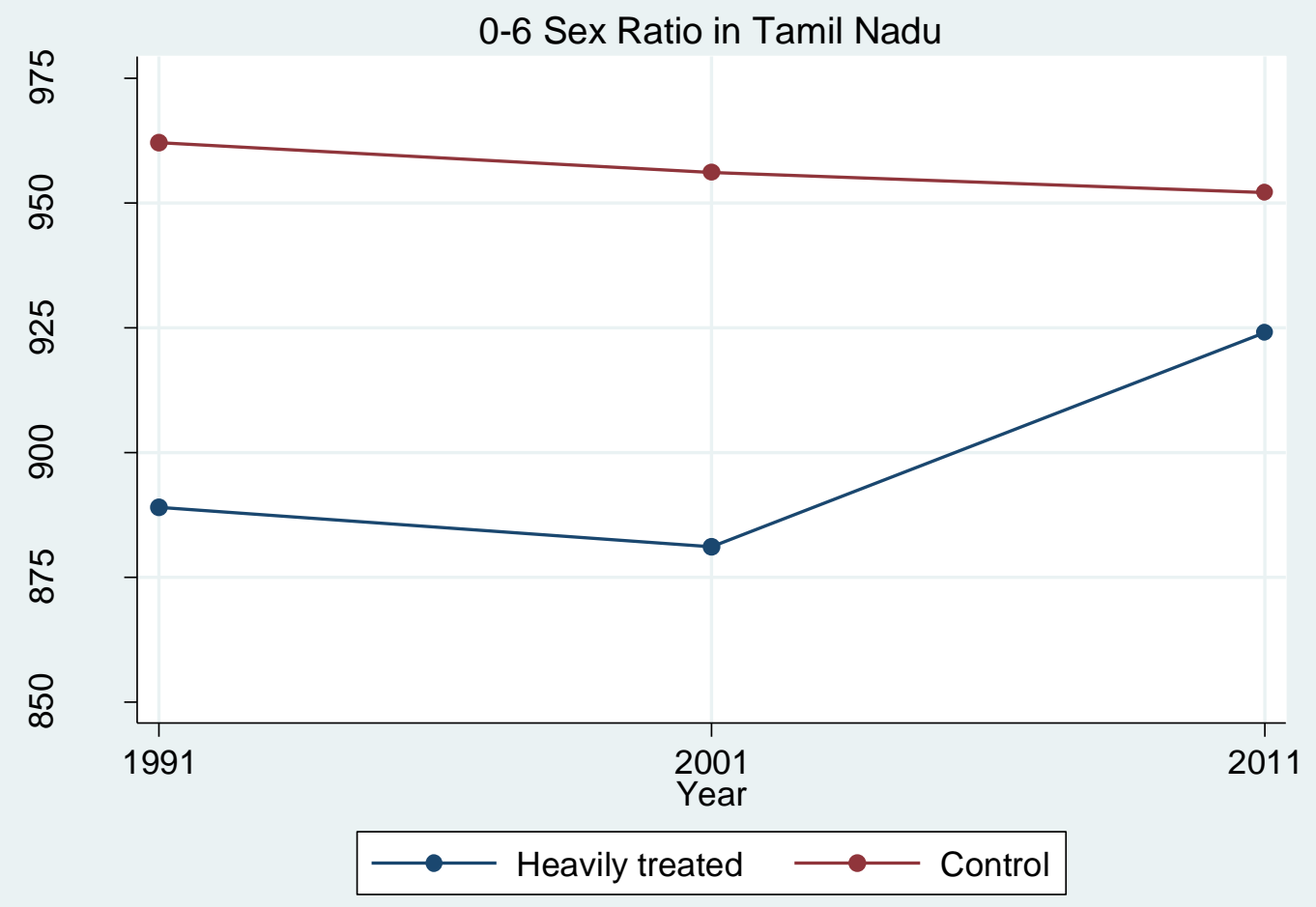

